
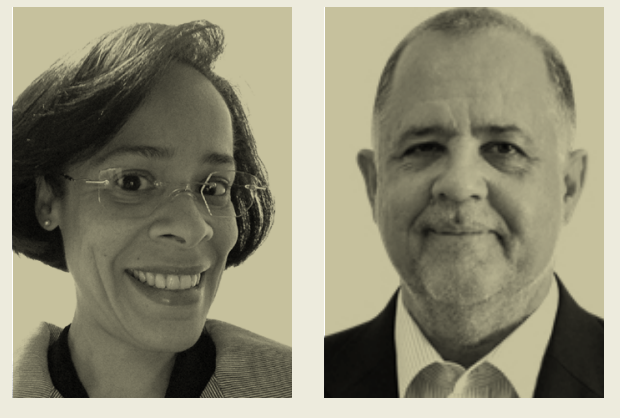

\title{
AVALIAÇÃO SISTÊMICA DE P\&D E INOVAÇÃO
}

Em uma empresa, recursos para Pesquisa \& Desenvolvimento e inovação ( $\mathrm{P} \& \mathrm{D}+\mathrm{i})$ são escassos e competem com outros investimentos de menos riscos e incertezas, não obstante sejam indispensáveis para a sustentação do crescimento do negócio. Por isso, devem ser utilizados e gerenciados com efetividade.

Para tanto, a avaliação de $\mathrm{P} \& \mathrm{D}+\mathrm{i}$ com base em indicadores é uma ferramenta essencial. Estratégica e sistemicamente conduzida, tal avaliação pode auxiliar na tomada de decisões de alocação para orçamento, portfólio e projetos de $\mathrm{P} \& \mathrm{D}+\mathrm{i}$ nas várias etapas de seu ciclo de vida. Apoia decisões estratégicas que impactam os ativos tecnológicos e mercadológicos da empresa $\mathrm{e}$ seu futuro competitivo.

A seleção dos indicadores mais adequados para os diferentes tipos de projetos de $\mathrm{P} \& \mathrm{D}+\mathrm{i}$ é o maior desafio de um processo de avaliação. Em primeiro lugar, porque não existem métricas universais que se apliquem a todos os tipos de projetos. Empresas que competem com inovações proprietárias investem em carteiras de projetos com distintos parâmetros de incerteza, risco e retorno. Isso reflete na adoção de métricas diversas para projetos com contribuições diferentes para o negócio. O que se espera de um projeto de inovação incremental de produto existente não é o mesmo que se anseia para um projeto de aprendizado e de redução de incerteza no uso de uma tecnologia emergente e potencialmente disruptiva. Em segundo lugar, diferentes grupos dentro da organização podem apresentar visões consideravelmente distintas quanto ao que é importante nas métricas de avaliação. Participantes de diversas funções e níveis de liderança devem ser envolvidos no processo de construção de indicadores e de execução da avaliação. Dependendo da natureza da colaboração, membros externos nos projetos de $\mathrm{P} \& \mathrm{D}+\mathrm{i}$ também podem trazer contribuições importantes. Deve-se assegurar a integração de diferentes pontos de vista (estratégico, tático e operacional) em diferentes dimensões da avaliação (processo, produto; financeira, não financeira; tangível, intangível), com a finalidade de construir indicadores consistentes com a vida real da empresa e alinhados com sua estratégia.

Ainda que sob supervisão e apoio da alta liderança, trata-se de um processo de negociação, validação e construção do consenso possível em torno de métricas/indicadores que poderão influenciar a competitividade da instituição e o cotidiano dos profissionais. Indicadores podem influenciar o comportamento de indivíduos. Por isso, um dos desafios é desenhar métricas específicas que se ajustem a cada nível e função envolvida com $\mathrm{P} \& \mathrm{D}+\mathrm{i}$, de forma que os colaboradores saibam exatamente o que deles se espera.

Avaliar não é simplesmente coletar dados, ranquear, pontuar e obter escores exatos. É um processo contínuo de reflexão estruturada, aprendizagem, negociação e construção de consenso em torno do aperfeiçoamento do processo de inovação, de mudança na empresa e seu gerenciamento. A avaliação é uma ferramenta essencial para otimizar e desenvolver boas práticas de gestão da $\mathrm{P} \& \mathrm{D}+\mathrm{i}$. Ela auxilia não apenas a medir o desempenho dos projetos $\mathrm{e}$ programas de $\mathrm{P} \& \mathrm{D}+\mathrm{i}$, mas, sobretudo, trabalha para o seu sucesso. 